\title{
VPI-7: The First Zincosilicate Molecular Sieve Containing Three-membered T-Atom Rings
}

\author{
Michael J. Annen, ${ }^{a}$ Mark E. Davis,* at John B. Higgins ${ }^{b}$ and John L. Schlenker ${ }^{b}$ \\ a Chemical Engineering Department, Virginia Polytechnic Institute and State University, Blacksburg, VA 24061, USA \\ b Central Research Laboratory, Mobil Research and Development Corporation, Princeton, NJ 08540, USA
}

VPI-7: the first microporous zincosilicate to contain 3-membered rings (3MR) is reported.

The synthesis of molecular sieves with framework densities (FD) lower than those currently attainable is an ongoing challenge in molecular sieve science. Currently, the minimum FD is 12.5 for CoAPO- $50^{1}$ which translates to a void space that occupies approximately half the crystal volume. Brunner and Meier ${ }^{2}$ have shown that there is a correlation between the minimum FD and the smallest ring size within the structure [minimum ring (MINR)]. If the correlation of Brunner and Meier is correct, then structures with three-membered rings (3MR) must be synthesized in order to achieve porosities greater than $50 \%$.

We have initiated a project aimed at finding and exploiting a suitable gel chemistry for the synthesis of $3 \mathrm{MR}$-containing materials. Beryllosilicates do promote $3 \mathrm{MR}$ formation as evidenced by the microporous mineral lovdarite ${ }^{3,4}$ and the dense minerals phenakite and euclase. ${ }^{5} \mathrm{~A}$ synthetic analogue of lovdarite has also been reported. ${ }^{6}$ However, many beryllium compounds are highly toxic and thus make it an undesirable element to work with. A synthetic aluminosilicate zeolite, ZSM-18, contains 3MR. ${ }^{7}$ Aluminosilicates, however, do not prefer the narrow $\mathrm{T}-\mathrm{O}-\mathrm{T}$ angles $c a .130^{\circ}$ which are necessary to form $3 \mathrm{MR}$. It is not likely that a general synthetic route to $3 \mathrm{MR}$-containing frameworks will employ aluminosilicate chemistry. We have observed that zincosilicate analogues of euclase and phenakite, namely clinohedrite and willemite, ${ }^{8}$ respectively, do exist. A synthetic non-microporous zincosilicate has also been reported. ${ }^{9}$ Thus, zinc appears to be a suitable substitute for beryllium in the formation of 3MRcontaining materials. We report here VPI- $7+$ the first microporous zincosilicate material to contain $3 \mathrm{MR}$.

VPI-7 is synthesized by heating a reaction mixture of composition 0.08 TEABr: $0.44 \mathrm{Na}_{2} \mathrm{O}: 0.28 \mathrm{ZnO}: \mathrm{SiO}_{2}: 44$ $\mathrm{H}_{2} \mathrm{O}$ for 12 days at $200^{\circ} \mathrm{C}$. The addition of TEABr (tetraethylammonium bromide) serves only to speed the rate of crystallization and is not incorporated into the product VPI-7. The $\mathrm{SiO}_{2}: \mathrm{ZnO}$ ratio of this sample is $3.3: 1$. VPI-7 crystals are typically in the form of fans composed of thin rectangular plates; the fans range in size from $\sim 10$ to $50 \mu \mathrm{m}$.

VPI-7 was exchanged with ammonium ions by refluxing in a $0.67 \mathrm{~mol} \mathrm{dm}^{-3}$ ammonium hydroxide- $-0.33 \mathrm{~mol} \mathrm{dm}^{-3}$ ammonium acetate solution for $4 \mathrm{~h}$ and the experimental X-ray powder diffraction pattern of $\mathrm{NH}_{4}-\mathrm{VPI}-7$ is shown in Fig. $1(a)$. The VPI-7 framework is tetragonal with maximum toplogical symmetry of $I \overline{4} m 2$. Ammonium exchanged VPI-7 has unit-cell dimensions of $a=7.179(1)$ and $c=40.62(1) \AA$, and has a FD $=17.2$. The $c$ dimension of VPI-7 is the largest framework repeat in any known molecular sieve topology. The unit-cell dimensions of VPI-7 are similar to those of lovdarite $(a=39.72, b=6.94, c=7.15 \AA$, orthorhombic basis). ${ }^{6}$ The Na cations present in as-synthesized VPI-7 are exchangeable, like in other molecular sieves, for such cations as $\mathrm{Li}^{+}, \mathrm{K}^{+}$or $\mathrm{NH}_{4}{ }^{+}$. The VPI-7 framework exhibits reversible $\mathrm{H}_{2} \mathrm{O}$ adsorption. At $P_{\mathrm{H}_{2} \mathrm{O}}=20$ Torr and $T=25^{\circ} \mathrm{C}$, K-VPI-7 reversibly adsorbs $\mathrm{H}_{2} \mathrm{O}$ with an adsorption capacity of 0.19 $\mathrm{g} \mathrm{g}^{-1}$.

$\dagger$ Present address: Chemical Engineering Department, California Institute of Technology, Pasadena, CA 91125, USA.

$\ddagger$ Virginia Polytechnic Institute Number Seven.
Lovdarite has maximum topological symmetry of $P 4_{2} / m m c$ and this topology is given the structure code LOV. ${ }^{1}$ VPI-7 is related to the LOV topology by translations of $a / 2$ and $b / 2$ along the mirror planes bisecting the layers of alternating 4and 6-MRs of the $\left(\begin{array}{lll}0 & 1 & 0\end{array}\right)$ and $\left(\begin{array}{lll}1 & 0 & 0\end{array}\right)$ faces of LOV, respectively. These manipulations transform all layers of alternating 4- and 6-MRs of the LOV topology into sheets of 5-MR and also doubles the $c$ dimension. Portions of the VPI-7 and LOV framework topologies are shown in Fig. 2.

A constrained distance and angle least-squares (DLS) ${ }^{10}$ refinement of atomic coordinates for VPI-7 was completed and the refined coordinates are listed in Table 1 . With space-group $I \overline{4} m 2$ it is not possible to have a $\mathrm{Zn}$-ordering

Table 1 Fractional unit cell coordinates for $\mathrm{NH}_{4}-\mathrm{VPI}-7(\overline{4} M 2) a=$ $7.179(1), c=40.62(1) \AA$

\begin{tabular}{llll}
\hline Atom & $x$ & $y$ & $z$ \\
\hline $\mathrm{T}_{1}$ & 0.2188 & 0.0000 & 0.0886 \\
$\mathrm{~T}_{2}$ & 0.2881 & 0.0000 & 0.1648 \\
$\mathrm{~T}_{3}$ & 0.0000 & 0.2895 & 0.1870 \\
$\mathrm{~T}_{4}$ & 0.0000 & 0.5000 & 0.2500 \\
$\mathrm{~T}_{5}$ & 0.5000 & 0.2890 & 0.0631 \\
$\mathrm{~T}_{6}$ & 0.5000 & 0.5000 & 0.0000 \\
01 & 0.0000 & 0.0000 & 0.0855 \\
02 & 0.2921 & 0.0000 & 0.1256 \\
03 & 0.3130 & 0.1822 & 0.0721 \\
04 & 0.5000 & 0.0000 & 0.1785 \\
05 & 0.1850 & 0.1839 & 0.1771 \\
06 & 0.0000 & 0.5000 & 0.1718 \\
07 & 0.0000 & 0.3172 & 0.2268 \\
08 & 0.5000 & 0.5000 & 0.0781 \\
09 & 0.5000 & 0.3172 & 0.0232 \\
\hline
\end{tabular}

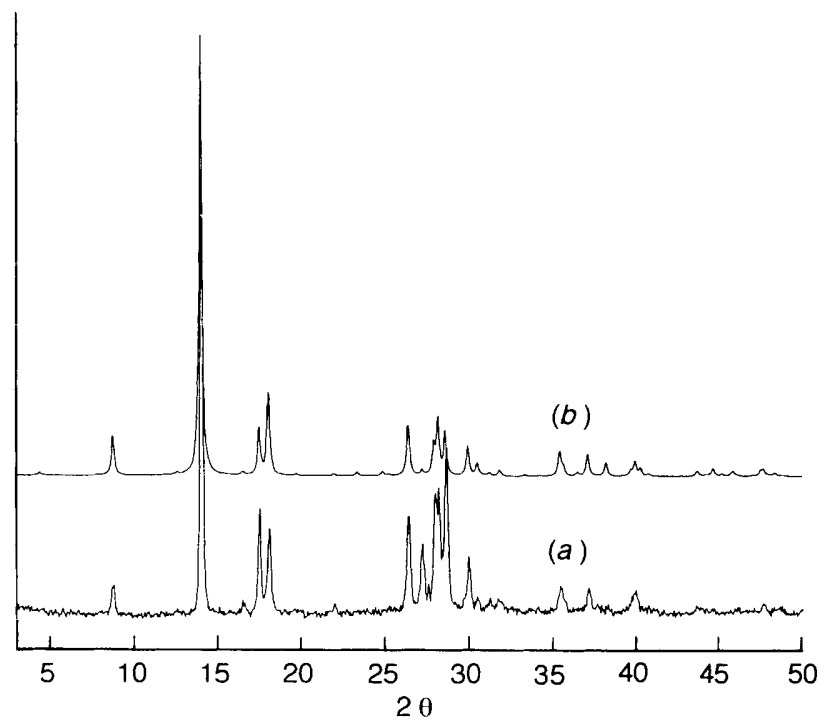

Fig. $1 \mathrm{X}$-Ray diffraction patterns of $\mathrm{NH}_{4}-\mathrm{VPI}-7$ : experimental $(a)$ and calculated $(b)$ 


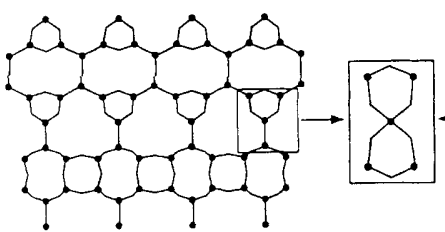

VP1-7

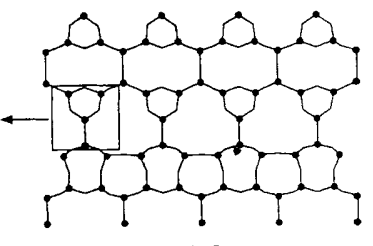

LOV
Fig. 2 Portions of the framework topologies of VPI-7 and LOV

scheme in VPI-7 which is analogous to the Be-ordering in lovdarite. Therefore, the DLS refinement was carried out with Si positioned in all T-sites. Figure $1(b)$ shows the calculated VPI-7 powder XRD pattern $(\lambda=1.54178 \AA)$. The powder pattern was simulated with $\mathrm{Si}$ positioned in all T-sites. Any differences in relative intensities between the experimental and calculated XRD patterns may be ascribed to effects from the presence of zinc, water and balancing cations, none of which are accounted for in the simulated pattern.

VPI-7 is the first microporous zincosilicate with $3 \mathrm{MR}$. It can be easily synthesized in the absence of toxic elements, e.g. Be and complex organic molecules (unlike lovdarite and ZSM-18, respectively). Thus, VPI-7 should provide opportunities to study the physicochemical properties of a molecular sieve which contains $3 \mathrm{MR}$. Also, the existence of VPI-7 proves the utility of zincosilicate chemistry in synthesizing 3MR-containing frameworks. Extensions of these results should lead from VPI-7 with MINR $=3^{+}$to new materials with MINRs of 3-3+ and with FDs below 12.5 .

M. J. A. acknowledges the Mobil Research and Development Corporation for financial support.

Received, 1st May 1991; Com. 1/02055B

\section{References}

1 W. M. Meier and D. H. Olson, Atlas of Zeolite Structure Types, Butterworths, 1987, p. 84.

2 G. O. Brunner and W. M. Meier, Nature, 1989, 337, 146.

3 S. Merlino, Eur. J. Mineral, 1990, 2, 809.

4 S. Merlino, Proceedings of The Sixth International Zeolite Conference, eds. D. H. Olson and A. Bisio, Butterworths, 1984, p. 747.

5 R. W. G. Wyckoff, Crystal Structures, Wiley, New York, 1969, vol. 4.

6 S. Ueda, M. Koizumi, Ch. Baelocher, L. B. McCusker and W. M. Meier, 7th IZC, Tokyo, Poster Paper 3C-3, 1986.

7 S. L. Lawton and W. J. Rohrbaugh, Science, 1990, 247, 1319.

8 C. Hang, M. A. Simonov and N. V. Belov, Sov. Phys. Crystallogr., $1970, \mathbf{1 5}, 387$.

9 S. Kohara and A. Kawahara, Acta Crystallogr., Sect. C., 1990, 46, 1373.

10 Ch. Baerlocher, A. Hepp and W. M. Meier, Program DLS-76, Eidgenössische Technische Hochschule, Zurich, revised March 1978. 